\title{
La Amazonía y el Pacífico en "La JangadA" de Julio Verne: UNA VISIÓN EUROCÉNTRICA
}

\section{Enrique Amayo Zevallos}

La novela amazónica de Julio Verne, "La Jangada", fue publicada en 1881. En ese libro uno de los personajes centrales es Manuel Valdez; además, entre los numerosos autores que Verne consultó para obtener información sobre la Amazonía, él cita "o brasileiro Valdez" quien había visitado y escrito sobre esa región en 1840. Coincidentemente, el cuzqueño José Manuel Valdez y Palacios, quien por razones políticas tuvo que huir del Perú, caminó gran parte de la Amazonía entre 1843 y 1844 (estas partes de su trayecto son exactamente las mismas que Verne trata en su libro). Ya en Río de Janeiro publicó, en portugués, entre 1844 y 1846 , el relato de su extenso viaje junto a otros temas históricos y literarios. En este trabajo se intentará determinar si el Valdez ficcional se basa en el verdadero y si las ideas de éste sobre la Amazonía de alguna manera influenciaron las del gran escritor francés.

"T $T$ he Jangada", the Amazonían novel by Jules Verne, was published in 1881. One main character in this book is Manuel Valdez. Besides this fact, among several writers Verne read to gather information on the Amazon, he quotes "the Brazilian Valdez" who travelled this region in 1840 and wrote about it. The Peruvian Jose Manuel Valdez y Palacios had escaped his native city Cuzco for political reasons. Running away from his persecutors, he walked a large portion of the Amazon from 1843 to 1844 (sections of his trip are exactly the same ones Verne mentions in his own novel). Finally, in Río de Janeiro, he published in Portuguese the narrative of his long trip together with some historical and literary topics, from 1844 to 1846 . Our intention in this paper is to try to establish whether the fictional Valdez is based on the real Jose Manuel Valdez y Palacios, whose ideas on the Amazon might have influenced the great French writer.

* El autor agradece al profesor José Barletti y al Dr. Estuardo Núñez. Les hago este agradecimiento porque, inadvertidamente $y$ en conversaciones informales, llamaron $\mathrm{mi}$ atención sobre la importancia de Verne para imaginar la Amazonía. 
na margem esquerda do Amazonas... na aldeia de Faro... e seu célebre Río de Nhamundas, no qual, em mil quinhentos e oitenta e nove, Orelhana conta que foi atacado por mulheres guerreiras que nunca mais tornaram a ser vistas... (Verne: 257)

\section{INTRODUCCIÓN}

La novela amazónica de Julio Verne, "La Jangada", fue publicada en 1881 (Gondim: 140). En ese libro, cuyo resumen daremos posteriormente, uno de los personajes centrales es Manuel Valdez. Además, Verne, entre los numerosos autores que consultó para obtener información sobre la Amazonía, cita a "o brasileiro Valdez" quien había visitado y escrito sobre esa región en 1840 (41).

El peruano Valdez y Palacios tuvo que huir de su país por razones políticas. Cuando escapaba de sus perseguidores recorrió gran parte de la Amazonía entre 1843 y 1844 . Coincidentemente estas partes de su trayecto son exactamente las mismas que Verne trata en su libro. Ya en el Brasil Valdez y Palacios publicó, en portugués, el relato de su viaje que incluye otros temas históricos y literarios. ${ }^{1}$

En este trabajo se intentará determinar si el Valdez ficticio se basa en el verdadero y si las ideas de éste sobre la Amazonía, consecuencia de su obligado viaje, de alguna manera influenciaron las del gran escritor francés. También se hará lo siguiente: Verne proporciona mucha información sobre diversos temas amazónicos desde una visión del mundo. Como aquí no

$1 \quad$ El título del primero de sus dos libros conocidos es el siguiente: Viagem Da Cidade do Cuzco A De Belem do Gräo Pará Pelos Ríos Vilcamayu, Ucayaly e Amazonas, precedido por hum bosquejo sobre o estado político, moral e litterario do Perí em suas tres grandes épocas. Pelo Dr. José Manuel Valdéz y Palacios. Tomo I. Río de Janeiro, Typografia Austral, Beco de Bragança., 15. 1844. El segundo: Viagem Da Cidade Do Cuzco, A De Belém No Grão Pará, pelos Ríos Vilcamayu, Ucayaly e Amazonas; Pelo Dr. José Manoel Valdez e Palacios. Río de Janeiro, Typ. De M.A. da Silva Lima, R.ua de S. José, 1846. 
será posible analizar toda esa información, se seleccionará aquella que, en nuestra opinión, hace relevante esa visión. Al mismo tiempo se la contrastará con los conocimientos que actualmente se tienen sobre esa región, especialmente con los proporcionados por la historia, para intentar determinar hasta que punto la información de Verne continúa vigente.

Resulta obvio que el gran personaje de "La Jangada" es la Amazonía. Como se verá, allí el Océano Pacífico aparece sólo de manera tangencial. Cuando se la lee se hace evidente que a Verne no le interesó tener allí a ese Océano como actor importante. En verdad él transformó al Pacífico en personaje central de su novela "Los hijos del capitán Grant" que no formará parte de nuestro estudio.

Lo dicho anteriormente vale para explicar lo siguiente. Este trabajo es parte de una investigación que se realiza desde hace algunos años. Ella se titula: "La formación histórica de la Amazonía y su problemática actual". Uno de los ejes de esa investigación de largo aliento es la creciente importancia estratégica que la Amazonía está adquiriendo en el escenario mundial. En ese nivel una de las hipótesis subyacentes es que esa importancia está determinada, en mucho, por los crecientes vínculos de la Cuenca Amazónica con la Cuenca del Pacífico (ésta última, centro de la economía mundial actual). Este último proyecto de investigación mencionado sí tiene en cuenta a "Los hijos del capitán Grant" porque esta novela, en relación al Pacífico, tiene importancia bibliográfica similar al que "La Jangada" tiene para la Amazonía.

Finalmente es oportuno advertir que aquí no ha podido usarse la versión original en francés; se utilizó una conocida traducción al portugués (ver bibliografía), que pudo conseguirse.

\section{ANTECEDENTES}

\section{A. La novela amazónica de Verne.}

"La Jangada" trata de las aventuras y desventuras del brasileño Jóao Da Costa, acusado de haber cometido el horrible Crimen de Tijuco. Con 
22 años, en 1826, en la ciudad de Vila Rica (hoy Ouro Preto en el Estado de Minas Gerais) ${ }^{2}$, Da Costa era empleado de la empresa estatal productora de diamantes (entonces, una de las más ricas del mundo). Un día, la recua que llevaba la producción a Río de Janeiro fue asaltada y todos los que la acompañaban fueron asesinados. Por su trabajo Jõao sabía de ese viaje (planeado en secreto). Por ser el único sobreviviente que conocía esa ruta, y a pesar de su inocencia, fue acusado, encontrado culpable y condenado a la horca. La noche anterior a ir al cadalso, logró huir a la Amazonía.

Da Costa cruzó la frontera y, usando el nombre de Jóao Garral, consiguió trabajo en la hacienda del portugués Magalhães, localizada muy cerca de Iquitos. Sus grandes cualidades morales y su disposición al trabajo impresionaron a Magalhães quien, antes de morir, víctima de la caída de un árbol, logró convencerlo para casarse con su única hija, Iaquita en 1830. Así Jôao se transformó en dueño de una gran hacienda que, gracias a su dedicación y espíritu empresarial, fue convertida en una unidad modelo, altamente capitalizada y productiva de madera, azúcar, café, caucho, tabaco, etc.. Muy moderna y progresista para su época y tanto que allí, como se verá después, Jõao a pesar de ser brasileño, voluntariamente estaba reemplazando la esclavitud (régimen legal y dominante entonces en su país) por relaciones salariales.

Garral y Iaquita (4 años más joven que él) tuvieron dos hijos: un hombre Bento y una mujer, Minha en la paradisíaca casa de esa hacienda (rodeada por jardines y un bosque con árboles, plantas, flores y animales de asombrosa variedad). Bento, a partir de los 12 años, fue a estudiar en Belén do Pará y regresaba todas las vacaciones a Iquitos. En la ciudad brasileña conoció y se hizo amigo íntimo de Manuel Valdez, un año mayor que él. En 1852, fecha central de la novela, éste último, el único del libro con nombre escrito en castellano (Manuel y no Manoel), era médico del ejérci-

2 En el Mapa Econômico do Brasil - Século XVIII, figura el nombre de Vila Rica. En el Mapa Econômico do Brasil - Século XIX, figura el de Ouro Pretro. (V.bibliografia: Novo Dicionário... 113 y 128). 
to de su nuevo país, Brasil (22). Manuel tenía 22 años y estaba nuevamente en la hacienda invitado por Bento. Fue entonces que descubrió que Minha también lo amaba y por eso juntos obtuvieron el permiso de los felices Jóao y Iaquita para poder casarse. Esta última, que igual que su hija sólo conocía la hacienda y la Aldea de Iquitos, decidió que la boda se haría en la ciudad de Belén (donde vivía la madre viuda de Manuel). Después de pensarlo mucho, Jóao aceptó. Pero, para hacer el viaje con entera seguridad, hizo construir una balsa (Jangada) gigantesca: "um enorme veículo... con as dimensóes de uma ilha"(45). Allí tendrían de todo: casa, la casa de los sirvientes (80 remadores indios y negros, algunos con sus familias), jardines, huerto, corral para aves y puercos, etc. Jõao y toda su familia harían el viaje. La familia también estaba compuesta por Manuel, considerado ya como un hijo desde hacía años, y por los acogidos: la sirvienta Cibele, vieja esclava liberta, y Lina una linda mulata quien, teniendo la misma edad de Minha, servía a ésta y además era su gran amiga. A esa familia se incorporó por casualidad el peluquero Fragoso quien deambulaba sin saberlo por tierras de la hacienda. Fragoso tenía graves problemas y decidió ahorcarse con una liana. En esas circunstancias Lina lo encontró por casualidad e interrumpió el suicidio. El buenísimo Jōao, conocedor de los hechos, lo invitó a incorporarse al viaje en la balsa. Fragoso terminó casándose con Lina. El fue quien, al descubrir sin saberlo la palabra Ortega, clave del criptograma que encerraba la verdad sobre el Crimen de Tijuco, salvó la vida de Jōao. Casi de la familia eran el también buenísimo Padre Passanha, quien hizo el viaje para jubilarse en Belén, y el piloto de "La Jangada", Araújo.

En el camino entre Iquitos y Manaos es acogido en "La Jangada" un hombre conocido sólo por su apellido: Torres, ex-cazador de esclavos que huían o, como se dice en portugués, un "ex-capitâo-de-mato"(12). El poseía el criptograma hecho por Ortega, el verdadero criminal de Tijuco. Ortega como parte de la tropa que vigilaba los diamantes, había fingido estar muerto el día del asalto; pero después, los otros miembros de la banda le robarían su parte del botín. Ortega, antes de morir, arrepentido escribió un criptograma y se lo entregó a su amigo Torres para que éste, a su vez, lo hiciera llegar a Joao quien, también mientras cazaba esclavos, había cruza- 
do la frontera y cerca de Iquitos había visto y reconocido a Garral por casualidad. Torres, con el criptograma en la mano, descubrió que podía volverse millonario chantajeando a Jóao. Una vez en la balsa conoció a Minha de quien se enamoró en secreto. Al darse cuenta de que ésta nunca lo aceptaría, decidió obligar a Jôao a que convenciera a su hija para que ésta aceptara casarse con él. Jōao Garral se negó porque eso iba contra todos sus valores y principios. Entonces Torres, lleno de rencor, lo denunció a la justicia de Manaos dónde, obligatoriamente, "La jangada" tuvo que detenerse.

Entonces Jõao tuvo que confesar su secreto. Su familia y todos los tripulantes lo respetaban, admiraban y amaban y por eso prometieron hacer de todo para probar su inocencia y liberarlo. Jõao fue apresado en la balsa y pisó la tierra de Manaos como prisionero; su crimen, por lo horrendo, era imprescriptible y en consecuencia tendría que morir en la horca. Torres huyó y se escondió en Manaos; Bento y Manuel lo buscaron hasta encontrarlo. En un duelo a machete, Bento lo mató. Al morir se descubrió que junto a su pecho llevaba una cajita de metal con un criptograma.

El Juez Jarriquez, apasionado por descifrar todo tipo de ingenios, era también especialista en criptogramas. Por eso era un lector del "Escarabajo de Oro" de Edgar Alan Poe ${ }^{3}$. El juez, convencido de la inocencia de Jôao Garral, por muchos días, utilizando el método de Alan Poe, intentó descifrar la enigmática carta encontrada en la cajita; finalmente concluyó que era imposible pues había sido hecha con una palabra clave que Torres se había llevado a la sepultura. Entonces Fragoso aparece en escena.

Fragoso, como peluquero, había viajado por toda la Amazonía. Por eso en algún momento recordó que tiempo atrás había conocido a Torres. Finalmente, viajó al lugar donde lo vió. Allí buscó y encontró al ex-jefe de Torres quien le dijo que, desafortunadamente, no sabía nada de éste porque, desconfiado de todo, sólo hablaba con su único amigo Ortega quien,

3 “uma novela do célebre romancista...verdadeira obra prima (do género)", Verne: 209. 
por desgracia, también había muerto. Fragoso, desconsolado y con las manos vacías, regresó a Manaos justo cuando Jõao Garral desfilaba rumbo al patíbulo. El peluquero buscó y habló desesperadamente con el juez diciéndole que no había encontrado nada que podría salvar a Jóao porque el único que podría haber sabido algo de Torres, su amigo Ortega, no existía más. El juez Jarriquez que había trabajado días enteros en el criptograma y que estaba atento a todas las posibilidades, al escuchar el nombre Ortega, que nadie había mencionado hasta ese momento, asumió de inmediato que podría ser la palabra clave. Y ésta era. De esa manera Jöao Garral=Jōao Da Costa fue salvado en el último minuto por un juez que, junto a ser honestísimo, era el sumum de la racionalidad. A partir de entonces "La jangada", con su feliz tripulación incrementada con un nuevo invitado, el Juez Jarriquez, continuó viaje hasta su punto final en Belén. Allí el Padre Pasanha realizó dos matrimonios: el de Manuel Valdez con Minha y el de Fragoso con Lina. Después, la gigantesca balsa fue desmontada y todo fue racionalmente vendido: la carga que llevaba (especialmente caucho, zarzaparrilla, extractos de plantas oleaginosas y de gomas, tabaco, azúcar, etc.) y la enorme cantidad de fina madera con la cual había sido construída.

Finalmente todos regresaron a vivir en la hacienda de Iquitos. En el último diálogo de la página final Manuel Valdez declara que allá ejercerá su profesión de médico.

\section{B. MANUEL VALDEZ.}

Es importante conocer brevemente a José Manuel Valdez y Palacios ya que su obra podría haber influenciado en Verne para que éste redactara su novela amazónica.

Valdez y Palacios nació en Cuzco a inicios del Siglo XIX. Probablemente vivió y estudió en París durante la década de 1820. Por esta formación universitaria Valdez y Palacios usaría siempre, junto a su nombre, la palabra "Doctor". Su obra sugiere que viajó intensamente por Francia, Inglaterra, Italia, Alemania, etc. a juzgar por su conocimiento de esos países y 
por sus abundantes citas, muchas en el idioma original, de Marmontel, Moliére, Byron, Walter Scott, Petrarca, Taso, Humboldt, Klopstock, Haller, etc. A partir de 1826 vivió en Lima siendo testigo de primer orden de eventos políticos que marcaron la vida de su país de forma indeleble: la salida de Bolívar y el inicio de la guerra de caudillos.

En 1843 entró a la Amazonía perseguido por las tropas del General San Román (uno de los presidentes-caudillos peruanos) convirtiéndose en otra de las víctimas de las guerras intestinas e intrigas políticas. De esta manera involuntaria y forzada inició su viaje, gran parte hecho a pie y llevando a su hijito de 7 años, que terminó después de 13 meses en Río de Janeiro. Probablemente murió en esa hospitalaria ciudad que lo acogió, en la década de 1850, sin cumplir con su deseo de regresar al Perú. ${ }^{4}$ Toda esta información ha sido proporcionada por Estuardo Núnez quien publicó la versión de sus obras en español (Núñez a y b). Es importarte mencionar que Núñez es el principal estudioso de Valdez y Palacios. ${ }^{5}$ Para producir este trabajo, y por ser más accesible, se usó la mencionada versión castellana. ${ }^{6}$

La obra conocida de Valdez y Palacios relacionada con el viaje (Valdez a) termina cuando va a iniciarse la travesía por el Río Ucayali. O sea que, comparándola con su título, falta la narrativa de la travesía por esa vía acuática hasta su unión con el Marañón para, una vez transformado en Río Amazonas, continua hasta llegar a Belén del Gran Pará. ${ }^{7}$ Sin embargo,

4 La narrativa de su aventura, calificada por él de cruel, fue publicada, como fue establecido, originalmente en tres partes entre 1844 y 1846. Sólo se tradujeron al castellano los dos volúmenes que han sido encontrados hasta hoy (v. Valdéz: a y b).

5 Pero Nuñez es también uno de los principales investigadores latinoamericanos del tema viajeros, siendo su producción muy amplia.

6 El original de Valdez y Palacios, obra rarísima, ha sido imposible de conseguir en Săo Paulo, que tiene un buen sistema bibliotecario y ciudad de residencia del autor. Se espera en un futuro próximo investigar en la Biblioteca Nacional de Río de Janeiro. Como alli publicó Valdez y Palacios hasta su muerte, es muy probable que pueda encontrarse su obra completa.

7 Es decir que lo conocido de la obra de Valdez y Palacios no coincide con la que, según el título, declaró que escribiría. Por eso se tiene la sensación de que lo conocido hasta ahora no constituye su obra completa. 
Estuardo Nuñez dice que la obra completa debe haber existido y debe haber sido consultada por franceses como el Conde de Castelnau quien, en su viaje por el Amazonas, prácticamente siguió la ruta hecha por el peruano:

Es probable que Castelnau, quien permaneció en el Brasil durante los años de 1845 y comienzos de 1846 y sólo salió de Lima hacia el Cusco para comenzar su empresa en Mayo de 1846, hubiera tenido a su alcance el libro de Valdez [y Palacios], aparecido en Rio de Janeiro en 1845... su derrotero le habría servido de guía utilisima al célebre explorador y cientifico francés (Núñez: XII y XIII).

Razones parecidas lo llevan a decir, allí mismo, que el libro del cusqueño sirvió de inspiración a "La Jangada" de Julio Verne. ${ }^{8}$

En relación a esa posible inspiración, de lo conocido de Valdez y Palacios, vale considerar lo siguiente. Raúl Porras Barrenechea también estudió a Valdez y Palacios. Según Nuñez, Porras concluía que el viajero peruano era:

un romántico completo, poseido del misticismo de la naturaleza y del amor, de las secretas correspondencias entre el paisaje y el espiritu, amante de la soledad del campo y desdeñoso de las costumbres livianas de la ciudad y de sus engaños, convencido del amargo destino de la humanidad y creyente tan sólo en la fuerza imponderable de la libertad humana... (Núñez a: XI).

Núñez opina también que el libro de Valdez y Palacios es el "libro de viaje más significativo del romanticismo peruano y tal vez una de las mejores obras en prosa de ese periodo". Allí, para la región que trata, la información y conocimientos geográfico-sociales y económicos mostrados son modernos

Núnez a : XIII. Sólo cuando se encuentre la obra completa de Valdez, pues parece que una parte esta perdida, podrá responderse definitivamente si influenció en el escritor francés para que escribiera LA JANGADA o no. 
y justos para la época pues sus escritos "revelan su visión comprensiva y moderna que se nutre de la emoción ante la naturaleza y ante el ambiente aborigen... ensayando así en algunas páginas la actitud indianista en que late un larvado impulso integrista"(Núñez b: XII y XV). Y la obra de Valdez y Palacios hace evidente todo eso. Pongamos algunos ejemplos. Su libro está dedicado al Instituto Histórico e Geográfico Brasileiro. Allí, en la Dedicatoria, dice:

Habiendo emigrado del Perú como consecuencia de la más atroz persecución que me hizo una de las facciones que han dilacerado ese país, caminando entre florestas y desiertos, por entre fieras y salvajes, pude al fin, después de trece meses de prolongada agonía, llegar al territorio de este vasto y opulento imperio... Esta pequeña obra, fruto estéril de tan crueles padecimientos, me atrevo a dedicarla a esta augusta corporación [el Instituto Histórico y Geográfico Brasileño] de hombres sabios e ilustres, con la confianza de que será... acogida con indulgencia... por los hechos históricos y geográficos que ella encierra (Valdez y Palacios a: 3).

En la introducción de su libro Valdez escribió lo siguiente (redactado en tercera persona) :

Relatamos únicamente lo que hemos visto... [y] tiene también el mérito de conservar la fisonomía original de una naturaleza inexplorada y del hombre primitivo, cuyas costumbres en vano se esforzaron en indagar los filósofos en el silencio de sus gabinetes (Valdez y Palacios: 5).

Puntualiza que en su viaje siguió una ruta no recorrida hasta entonces:

El Ucayali, que bajando de las cumbres de los Andes con el nombre de Vilcamayo, y engrosándose con la confluencia del Apurimac y sus demás tributarios, forma el brazo mayor del soberano de los rios, el gran Amazonas, no fue navegado hasta a hora por ninguna persona, en la parte que riega desde la boca del Pachitea hasta la misión de Cochabambilla... y ya que tuve la suerte de ser el primero en realizar este viaje, creo que es mi 
deber no dejar pasar ninguna noticia que pueda redundar en algún bien (Núñez a: 6 y 7 ).

Establece claramente el objetivo de su libro que, al dar claramente cuenta del recorrido del Cuzco al Pará, permitiría que el conocimiento de esa región posibilitaría su incorporación plena a las economías del Brasil y del Perú. Escribe textualmente:

... Pero, que provecho, me dirán, resultará de un viaje no científico, tan sólo producto de la casualidad? Respondo que en casi todas las cosas humanas la casualidad casi siempre da el primer paso... Trazado el recorrido del Cuzco al Pará, determinados los lugares y las distancias aproximadas, indicadas las producciones posibles de convertir en articulos de comercio, nacidas con tanta abundancia en aquellos climas deliciosos, designada la manera de emplear los propios salvajes, llevándolos a contribuir en todo lo posible, anotadas por último las precauciones y lo necesario para hacer la navegación... entonces las aguas... se verán surcadas por embarcaciones llenas de vida y actividad; entonces las ricas producciones de estos paises, aumentadas y mejoradas por la mano de la industria, multiplicarán también los goces de la existencia (Núñez a: 6 y 7).

Casi al finalizar la introducción señala que su libro incluirá también:

... la descripción de lugares antes desconocidos en la geografia, la enumeración minuciosa y evocativa de singulares costumbres muy poco semejantes a las de otras naciones selváticas esparcidas por la superficie del globo, la narración finalmente de cosas y aventuras extraordinarias sucedidas durante una jornada de mil y tantas leguas... Con relación al viaje debo advertir que los oficiales de la Marina Inglesa Maw y Smith realizaron también uno desde el Perú hasta el Brasil por el Río Amazonas, habiendo ambos publicado sus trabajos...(Núñez a: 7 y 8).

La narrativa de Valdez y Palacios, donde muestra que conocía parte de la bibliografía amazónica publicada en su tiempo, está llena de detalles y 
es casi fotográfica al describir costumbres, especialmente indígenas. Los ejemplos muestran que su obra está impregnada por una visión trágica de la existencia así como por la idea de progreso. Al mismo tiempo, tiene una posición poco paternalista en relación a los indios amazónicos: quiere entenderlos para poder usarlos y por eso, a pesar de tildarlos de salvajes (como casi todos lo hacían entonces), los estudia minuciosamente. Allí está la razón para ubicarlo entre los precursores del indianismo. Hay que señalar también que tenía una visión democrática del conocimiento y por eso creía que era su deber contribuir a difundirlo. Y por su posición siempre favorable al aprovechamiento simultáneo y sistemático de los territorios del Brasil y del Perú podría también ser considerado un precursor de la integración. Por otra parte, su obra es testimonial ya que es resultado de su experiencia directa en la Amazonía.

\section{CONTENIDO DE LA NOVELA DE VERNE}

Es bien sabido que Julio Verne es uno de los padres del género novelístico conocido como ciencia ficción. Cuando se lee "La Jangada" podría tenerse la impresión de que no es una obra de madurez de ese autor. Sin embargo ésta, como sus otras novelas, muestra al escritor poseedor de una información casi enciclopédica. Parecería que él, que por lo que se sabe fue un extraordinario "ratón de biblioteca" que conoció casi todo por experiencia indirecta, tenía interés por todas las disciplinas humanas orientándose, al estudiarlas, por el paradigma del Positivismo Cartesiano. "La Jangada” presenta un cuadro vasto de la Amazonía donde se destaca la información histórica, geográfica, botánica, zoológica, hidrológica, criptográfica, etc. Allí la idea de progreso promovida por los descendientes de los europeos (o sea, al fin y al cabo por Europa) permea toda la obra.

Lo anterior intentará mostrarse estudiando algunos tópicos de esa novela. Pero antes importa subrayar lo siguiente. Sería un error, por ejemplo, juzgar a "La Jangada" como una obra histórica ya que ella, por su naturaleza, no tiene el rigor metodológico que esa disciplina exige. Para 
ejemplificar, analicemos la frase del epígrafe. En verdad los acontecimientos allí narrados corresponden a 1542, exactamente al 24 de junio de ese año y no a 1589. '. Y el que "cuenta" no fue Orellana sino el Padre Carvajal, cronista de la expedición de conquista que incorporó la Amazonía a la historia de Occidente (Carvajal: 97-101). Lo que se quiere decir con esto es que, desde el punto de vista de cada una de las ciencias arriba mencionadas, probablemente la información que Verne proporciona en "La Jangada" no es muy rigurosa. Pero eso no es un límite para esta gran obra de ficción.

En ese libro se tocan puntos como los siguientes.

A. El Río Amazonas es descrito minuciosamente y siempre en términos superlativos. Verne dice: "E o maior Río do mundo" nacido na "enorme cordilhera dos Andes", va a perderse "a oitocentas léguas de distância dali, no Océano Atlantico" (38); la Cuenca Amazónica es "imensa e rica... não tem rival no mundo" (42).

En relación al nacimiento del río, se lee: "nasce no Peru, no... Lago Lauricocha" (39). La Amazonía, un territorio inmenso y magnífico, despertó siempre el interés de aventureros y científicos quienes, entre otras cosas: "exploraram o curso do Rio, subiram diversos de seus afluentes e reconheceram que são navegáveis os principais tributarios" (42). Varios de ellos dejaron escritos y Julio Verne muestra que conocía a muchos de ellos. Aqui va a ponerse la relación consultada por él y transcrita según el orden en que fueron apareciendo en "La Jangada" y con los nombres usados por Verne: el profesor Agassiz, el padre Durand, en el Siglo XVI Orellana, en 1636-37 el portugués Pedro Teixeira, en $1743 \mathrm{La}$ Condamine con sus compañeros Bouguer y Godin des Odonais, en 1798 Humboldt y Bonpland (40-41). Ahora, debido a que lo que viene es relevante para este trabajo, se cita

Será que esta última fecha es un error de la versión en portugués? Considérese que ella es: "uma traduçáo redutora... [que] comprime o texto, tornando-o árido" (Gondim: 165). O sea que no es fiel al original francés. 
textualmente esa relación: (41-42). "em 1827, Lister-Maw; em 1834 y 1835 o inglês Smith; em 1844, o tenente francês comandante da Bolonhesa; o brasileiro Valdez, em 1840; o francês Paulo Marcoy de 1848 a 1860; o imaginoso Biard, em 1859; o professor Agassiz, de 1865 a 1866; em 1867, o engenhero brasileiro Franz Keller-Linzenger e, finalmente, em 1869 o doutor Crevaux... "

Contrastando lo anterior con la información que se posee en la actualidad, podría decirse lo siguiente. Si bien el río Amazonas nace en los Andes peruanos, su longitud no tiene 800 leguas: tiene muchas más. Cada legua tiene $5 \mathrm{Kms}$. Y por lo tanto 800 leguas serían iguales a 4,000 kms. ${ }^{10}$ O sea que la distancia dada por Verne es de sólo 600 leguas (3,000 Kms.). Aquí vale anotar que el viaje del peruano "fue de mil y tantas leguas... (Valdéz y Palacios a: 8).

¿Por qué esa diferencia de magnitud tan grande? La explicación tal vez podría estar en que Verne da como lugar de nacimiento del río Amazonas a la Laguna de Lauricocha. Sucede que en el tiempo en que vivió el novelista francés todavía se discutía si esa laguna sería el origen del río. Pero ya está demostrado que en Lauricocha en verdad nace el río Marañón (que tiene una extensión de 1,800 Kms.). La moderna geografía universal acepta que de la unión de ese río con el Ucayali (de casi 3,000 Kms.) en el Puerto de Nauta, se forma el río Amazonas. Por lo tanto su afluente principal, por ser el mas remoto, es el Ucayali. Y medido desde sus orígenes en Arequipa, en el Nevado Mismi de 5,597ms.s.n.m., resulta que la longitud total del Amazonas es de 7,025 Kms. Lo anterior también podría explicar que, aun cuando las distancias dadas por Verne y por Valdez y Palacios no

10 Paulo Roberto Martini y José Wagner García, investigadores del reputado Instituto Nacional de Investigaciones Espaciales (INPE) del Brasil, determinaron en 1995 que, medido el Amazonas al igual que todos los ríos o sea desde el nacimiento de su afluente más remoto, sería también el más largo del mundo con 7,025 Kms (o mas de 1,400 leguas). Esos investigadores, con la ayuda de métodos y tecnologías muy sofisticadas, comprobaron una vez más lo que la geografía peruana conocía desde hacía mucho tiempo (V. Amayo 1993 y 1995: 56). 
son exactas, la del primero es más pequeña porque mide al Amazonas a partir de su formador más corto (el Marañón) y la del segundo es más grande porque lo hace desde el más largo (el Ucayali).

La relación de exploradores y científicos de la Amazonía citados por Julio Verne interesa en este trabajo porque allí menciona a los brasileños Valdez y Franz Keller-Linzenger. Ahora, parece evidente que el 'brasileño Valdez" citado por Verne es el peruano Valdez y Palacios; la confusión del escritor francés podría ser consecuencia de su conocimiento de la edición original del cusqueño que, como vimos, fue publicada en portugués y en Río de Janeiro (entonces, capital del Brasil). Debió tomarlo por brasileño; Estuardo Nuñez también señaló eso en sus escritos. ${ }^{11}$

B. La Hacienda de Iquitos en "La Jangada" es un lugar paradisíaco. Y lo es principalmente porque allí no existe ninguna contradicción originada por el proceso de trabajo. Esa hacienda, y el mundo productivo que va

11 En relación a lo anterior. Neide Gondim, profesora de Literatura Amazonense de la Universidad de Manaos, en 1994 publicó su trabajo ya mencionado. En el capítulo "Oitocentas Léguas pelo Río Amazonas" analiza "La Jangada”. Hasta donde se tiene información parecería que ése es el único trabajo sobre el tema escrito en el Brasil. Neide dice que la novela de Verne: "é pontuada por datas. Säo citados diversos viajantes, como Humboldt, Agassiz, padre Durand, Orellana, Pedro Teixeira, La Condamine, Lister-Maw e-Smith, Paul Marcoy, Emílio Carrey, o brasileiro Franz Keller-Linzenger" (Gondim: 141). Es evidente que en esa relación Neide hizo desaparecer "o brasileiro Valdez" . ¿Porqué? ¿Porqué de solo dos brasileños citados por Verne, Neide hizo desaparecer a uno? ¿Porqué lo hizo desaparecer sí, hasta dónde se sabe, no son muchos los de ese país (ni de América Latina) que han explorado la Amazonía? Sería que Neide consideró que Verne había cometido un lapsus o que simplemente se equivocó? ¿O consideró que Valdez sí existía pero que, infelizmente no era brasileńo? ¿O sería que a ella no le interesaba investigar la posibilidad de invenciones no-europeas de la Amazonía? Es casi imposible que "los brasileños" mencionados por Verne no llamen la atención de cualquier investigador de esa nacionalidad que lea ese libro. Siendo así en un trabajo dedicado a esa novela, hacer desaparecer a uno de los mencionados en ella, requeriría mínimamente de una nota explicatoria. Pero nada de eso hizo Neide. Por eso es posible imaginar que ella descartó a Valdez por falta de curiosidad. De haberla tenido, tal vez su investigación hubiera tomado otros rumbos descubriendo, por ejemplo, que Valdez existió, etc. Eso probablemente habría hecho que Neide produjera un libro aún más rico y con mayor rigor. Es bien sabido que la falta de curiosidad limita la investigación. 
apareciendo a lo largo del viaje en la novela, es casi siempre pacífico y feliz. Esto principalmente porque los indios y negros (presentados generalmente como sirvientes), aceptan con docilidad (y hasta con felicidad) el dominio de los blancos (de origen portugués en la novela); ellos son los portaestandartes de la civilización en la Amazonía. Obviamente esto es una utopía reaccionaria. ${ }^{12}$

En Verne esa utopía está determinada, en mucho, por la visión del mundo dominante en Europa en los momentos en que escribió su libro. Recuérdese que "La Jangada" fue publicada en 1881, o sea en los años en que estaba desarrollándose el capítulo de la historia mundial conocido como consolidación y expansión de la fase imperialista. En esos años, según Kiernan, por ejemplo, gran parte de los europeos y del hombre blanco en general justificaban su expansión y dominio del mundo por ser mera consecuencia de su obligatoria misión (carga) de llevar y difundir su civilización ("única y verdadera") por el planeta habitado en su mayoría por noblancos o salvajes. La explotación de los mercados del mundo no era el dínamo de ese gigantesco proceso de expansión. No. Era la tarea civilizatoria que, para realizarse, desafortunadamente tenía que usar cualquier medio. Kiernan cita por ejemplo a W.P. Andrew quien, en 1880, publicó Our Scientific Frontier. Andrew se definía como un hombre de paz; sin embargo él consideraba natural afirmar que era "...misión británica [europea]... expandir entre los salvajes el poder de ese gran civilizador, la espada" (Kiernan: 312). El novelista francés compartía esa visión; para él "a guerra, como se sabe, foi durante muito tempo o mais seguro e rápido veículo de civilizaçāo..." (86). Y esa tarea civilizatoria tenía naturalmente que ser recompensada por los pueblos que tenían la suerte de que se la llevara, no interesaba si volun-

12 Cualquier estudio histórico serio muestra que, por el contrario, los pueblos amazónicos, a pesar de ser masacrados bárbaramente y superexplotados, desde el inicio de la conquista resistieron de diversas formas al depredador invasor occidental (v. por ejemplo Barletti: 1992). Y, como la historia muestra, la destrucción de la Amazonía hasta los preocupantes niveles de la actualidad (relacionados hasta con el futuro de la humanidad) es precisamente consecuencia directa del avance de la "civilización" occidental en ella. 
taria o involuntariamente. ${ }^{13}$ En esa visión ideológica desaparecían las relaciones de explotación. Hábilmente eran reemplazadas por "principios éticos" o sea, por la carga, responsabilidad, misión de los occidentales de ser los depositarios y difusores de LA CIVILIZACION por el mundo. Por eso en los periódicos de la época, principalmente ingleses, no era rara la publicación de dibujos que mostraban a un poderoso hombre blanco cargando en sus espaldas al mundo recurriendo así, subliminalmente, al mito bíblico de pueblo (o raza) escogida.

La hacienda de Iquitos y el mundo del trabajo descritos en "La Jangada" coinciden con el modelo esbozado anteriormente.

C. Los blancos, indios y negros son tratados de manera diferente en esa novela. Los blancos, como los ya mencionados, tienen rostro, nombre, biografía. O sea que ellos para el bien (la familia de Garral=Costa) o para el mal (Torres) son los que cuentan porque, parece decir la novela, son los únicos que hacen la historia.

Por el contrario, indios y negros no tienen nombre ni rostro. La novela parece decir que todos ellos son una masa, en el sentido de que para los blancos, los hombres de color son indistinguibles uno de otro porque todos son iguales. También son presentados como simples brazos. Así masa y brazos adquieren la forma de trabajadores y desarrollan su habilidad sólo cuando el cerebro de un hombre blanco los dirige. Verne dice, por ejemplo, que construir la inmensa jangada seria "... trabalho fácil. Sob a direção de Jôao Garral, iam os indios serviciais da fazenda desenvolver sua habilidade, que é incompararável. Êstes indígenas são habilidosos operários... "58). O sea que los indios para desplegar sus habilidades humanas necesitan del hombre blanco. Como los niños, tenían que ser orientados siempre por un responsable ya que eran "grandes crianças [niños grandes]" (91).

13 Los imperialistas del Siglo XIX denominaron a ese esquema ideológico de carga del hombre blanco. Los glorificadores y propagandistas del imperialismo como Rudyard Kipling dedicaron hasta poemas a ese esquema (v. Hobsbawm: 122) 
Julio Verne no llega al extremo de presentar a los indios con características animalescas. En cambio muchos exploradores occidentales de la Amazonía como los naturalistas alemanes Spix y Martius, que viajaron por el Brasil entre 1817 y 1820 llegando hasta esa región, si los veían así. ${ }^{14}$ Verne representa a los indios como seres infantiles que necesitan conducción sin las características simiescas que les atribuyen esos naturalistas alemanes. Pero en esas dos visiones lo que existe es una diferencia de grado (cuantitativa) y no cualitativa. Ambas coinciden en considerar al indio como inferior. Y es que ése era el espíritu dominante en la Europa de entonces. En un excelente libro que trata ese período se muestra que: "a novidade [para o Ocidente do] Século XIX era que os não europeus e suas sociedades eram crescente e geralmente tratados como inferiores, indesejáveis, fracos e atrasados, ou mesmo infantis" (Hobsbawn: 118).

Podría decirse que los criterios de.Verne para los indios valen también para los negros ("prêtos" en portugués). Por ejemplo, en la descripción de la hacienda de Iquitos los presenta siempre juntos y sirviendo (casi como si la naturaleza los hubiera hecho para desempeñar esa actividad). Así, el novelista dice: "havia ... cêrca de 100 indios... assalariados para o amanho da fazenda, e 200 prêtos que ainda nāo eram livres, mais cujos filhos não nasciam escravos. Jöao Garral precedera o govêrno brasileiro...."(31). Y también dice que los remadores de "La Jangada" serán 40 indios y 40 negros pues: “... eram necessários aquêles cento e sessenta braços para a manobra das compridíssimas varas, destinadas a conservar a enorme [balsa] a igual distancia das duas margens... "(61).

Los únicos no blancos de la novela que tienen nombre (pero no apellido) son Cibele, la sirvienta ex-esclava, y Lina, la mulata sirvienta de

14 En el libro de una distinguida investigadora de esos naturalistas, ilustrado con bellas reproducciones extraídas del facsimilar del libro de Spix y Martius, ella comenta así uno de esos dibujos: "Dança dos indios puris. Litografía... Nota-se que os indios são representados com corpos absolutamente deformados, desproporcionais e com expressão de demência, ausente de traços fisionomicos que os individualizem, parecendo-se mais com figuras animalescas e monstruosas..." (Lisboa: 151). 
Minha. O sea, son casi blancos (tienen nombre) pero no lo son enteramente (les falta el apellido). De cualquier manera ellas ya son parte de la familia blanca o sea, cultural y/o étnicamente fueron blanqueadas. O, en otras palabras, fueron aceptadas e incorporadas a la civilización occidental (única manera, parece decir la novela, de entrar en el camino del progreso).

D. Progreso, significa para Verne una fatalidad ya que sólo puede realizarse en:

... detrimento das raças indigenas. No Alto Amazonas bastantes raças de indios tem desaparecido já.. No Putumaio... os Iauas abandonaram-no... e os Maoos desertaram de suas margems... o Río Tocantins acha-se quase despovoado... poucas relíquias há já da grande nação Umaua... nas margems do Río Negro, regiäo onde chegou a haver 24 naçôes diferentes, não aparecem já senão mestiços... (42)

O sea que conforme avanza el progreso (símbolo de Occidente) el indio y todos los no-blancos retroceden hasta que, finalmente, tendrán que desparecer. Desafortunadamente, parece decir la novela, desaparecerán pero dejarán en su lugar a los mestizos. Esa es una infelicidad que tiene que ser aceptada porque es la ley del progreso. Su visión es darwiniana y en su nombre acepta y justifica la desaparición de todos los pueblos no-occidentales. En sus palabras: "É a lei do progresso. Os indios hão de desaparecer. Diante dos conquistadores do faroeste somen-se os indios da América do Norte. Talvez um dia os árabes sejam aniquilados pela colonização francesa” (43). El históricamente lento y fatal proceso de aniquilación de los indios amazónicos (y de todos los no-occidentales en general) va a generar sin embargo a los "tristissimos produtos do cruzamento de raças" (90) o sea, a los mestizos.

El novelista francés ve al progreso de una manera positivista. Al mismo tiempo, ve la cuestión racial en términos de pureza. Esos dos elementos, parten del esquema ideológico eurocéntrico (y mas: occicéntrico), son los que le hicieron descartar totalmente la posibilidad de que esa fatalidad 
histórica, descrita por él, finalmente no se realizase y no se haya realizado hasta hoy. ${ }^{15}$

El autor de este trabajo, un mestizo, no sabe si constituye un ejemplo del "tristísimo producto del cruzamiento de razas". Lo que sí sabe es que existen tautologías como las siguientes. Primera: conforme pasa el tiempo, son crecientemente mestizas (racial y/o culturalmente) las poblaciones de los países amazónicos y de América Latina en general. Segunda: eso es un fenómeno universal y conforme se acelere la globalización, el mestizaje también se incrementará en el mundo. Otra cuestión, que parece evidente por si misma aun cuando aquí la plantearemos sólo como hipótesis, es que para la supervivencia de los indios amazónicos (y de los indios en general) la ayuda de muchos mestizos ha sido fundamental. Decimos esto partiendo de la consideración de que en fenómenos latinoamericanos como los siguientes: fundación de países, indianismo e indigenismo, recuperación del pasado pre-colombino y de la "historia de los vencidos", muchos mestizos han desempeñado un papel de primer orden.

La concepción eurocéntrica de Verne no se limita a esos dos aspectos. Tiene que ver también con la idea de que el progreso implícita y necesariamente significa tecnología (entendida como conocimientos en el sentido de saber hacer o "know-how", técnica en el sentido de instrumental y el correspondiente proceso que envuelve todo lo anterior) moderna. Mas todavía pues la idea de progreso tiene inherente el significado siguiente: lleva su tecnología a todos los lugares a donde llega; en esa idea está implícita que esos lugares de llegada no la poseían. En otras palabras: los europeos (u

15 Por ejemplo, los indios amazónicos: “... al momento de la conquista de América, la Amazonía estaba ocupada por no menos de 2,000 pueblos indigenas y se ha estimado que su población sobrepasaba los 7 millones de personas. Hoy... a pesar de haber tenido que enfrentar condiciones claramemte adversas para su supervivencia y desarrollo, sobreviven en la región aproximadamente 400 grupos étnicos... "(Amazonía sin mitos: 31). La población indígena amazónica estimada a inicios de la década de 1990 era de 935,939 personas (Ibid: 34). 
occidentales) llevaban naturalmente su tecnología a todos los lugares a donde llegaban los que, antes de eso, o no la poseían o la poseían de manera muy limitada (esto es parte esencial del fenómeno conocido como progreso). En el caso de "La Jangada", los indios amazónicos son presentados como poseedores de gran habilidad manual (típica de niños-grandes). Fuera de esa habilidad, parece decir la novela, tecnológicamente no poseían nada. ¿Será eso cierto o allí nuevamente se está confrontando a otra trampa ideológica eurocéntrica?.

El novelista francés muestra siempre su erudición dando muchos detalles. En esta parte interesa mostrar cómo fue construida la jangada. Aquí no va a repetirse la minuciosa descripción de Verne de ese proceso; sólo se recuperarán algunos detalles.

La jangada fue hecha: "de madeira, media 300 metros de comprimento por 20 de largura ou uma superficie de 6,000 mts.2. Realmente, era uma floresta inteira..." (59). Y lo era porque, para hacerla, fueron derrumbados muchísimos árboles. Transformados en troncos eran: "separados segundo a sua natureza e o seu grau de flutuabilidade, [e depois] simétricamente enfilerados na margem do Amazonas..." (46). Posteriormente los troncos fueron amarrados: "presos uns a outros por cabos de piaçava, que sāo [muito] sólidos... Esta matéria, que é feita da fibra de certa palmeira, abundantíssima nas margems do Río... flutua, resiste à imersão, e é de baixo preço... " (59). Clavos no se usaron para mantener unidos los troncos. ¿Quiénes la construyeron? Al respecto se lee lo siguiente:

... ia ser fabricado um enorme veículo... nesta jangada, mais segura que nenhuma outra embarcação... mais vasta que 100 canoas ligadas, é que João Garral ia embarcar con a família, pessoal e carga... Joäo... mandou chamar um indio, que era o principal feitor da fazenda: dentro de um mês — disse-é preciso que a jangada esteja pronta para navegar. Hoje principiaremos, Senhor Garral - respondeu ... . A tarefa era árdua [o feitor] e cêrca de 100 operáRíos, entre indios e prêtos... fizeram verdadeiras maravilhas (45-46). 
Posteriormente agrega: "Grande parte da floresta fôra abatida. Os carpinteros iam agora iniciar o trabalho de construir a jangada. Trabalho fácil. Sob a direção de João Garral, iam os índios serviciais da fazenda desenvolver a sua habilidade... " (46). ${ }^{16}$

Por lo que nos hace saber Verne la jangada sin duda era una balsa enorme. Inspirada en las típicas embarcaciones indígenas amazónicas, fue construida con materiales indígenas (troncos), con técnicas indígenas (ataduras de lianas en vez de clavos), con técnicos indígenas (los carpinteros quienes, con su habilidad, mostraban poseer el "know-how"), con trabajo principalmente de indígenas (y también de negros), administrado y orientado por un indígena (el "feitor" quien, hasta por el nombre, literalmente era el hacedor). Sin embargo el novelista da casi todo el mérito a la dirección: "os trabalhos de construcção haviam-se realizado sob a direção de João Garral" (60).

La información presentada encima hace evidente que Garral no tuvo prácticamente nada para dirigir. Salvo que se considere dirección al hecho de mandar que la jangada se hiciera en un determinado plazo. En verdad con ese acto lo que hizo fue pasar a expropiar tanto el trabajo como la tecnología indígena. Fue un proceso ciego y por eso presentado por Verne como natural. Ciego porque al no reconocer a los indios como los seres que lo hicieron casi todo (no los reconoce al punto que ni nombre les da y, de ese sino, ni el "feitor" escapa), resulta más que natural atribuirle el mérito a João Garral (o sea, al blanco, representante de la avanzada civilizatoria europea). En otras palabras, al no nominar a los indios no los está reconociendo como seres individuales con voluntad propia y por lo tanto sus existen-

16 Importa considerar la información siguiente. Balsas, canoas y barcos son tema esencial de discusión entre los estudiosos de la navegación acuática; en ese sentido es iluminador el libro del investigador noruego Heyerdahl (v. bibliografía). La balsa es una embarcación que responde a problemas de habitats no-europeos y por eso no se corresponde con el barco, paradigma de la navegación del Viejo Mundo. 
cias casi no tienen importancia. Al hacer exactamente lo contrario con el blanco, lo está transformando en la existencia directa de todo el proceso. Así, lo que Verne presenta corresponde casi al modelo paradigmático que retrata los mecanismos de Occidente para expropiar el trabajo y la tecnología de la América Indígena (y, por extensión, del mundo no-occidental en general). ${ }^{17}$

Específicamente en "La Jangada" se describe así al método indígena amazónico para extraer el caucho (o "borracha” que está en el árbol llamado "seringueira", nombres usados en el Brasil):

... os indios haviam metido mãos á obra. Deram golpes no tronco das seringueiras e fixaram por baixo da ferida pequenos vasos que deviam ficar cheios, no espaço de 24 horas, de um suco lácteo, que se pode também colher por meio de um bambu ôco e de um recipiente colocado ao pé da árvore. Colhido o suco, os indios, para que não se isolem suas particulas resinosas, submetem-no a uma defumação sobre fogo de nozes de palmeira açai. Enrolando o suco sôbre um eixo de madeira e movendo-o de um lado para o outro, na fumaça, produz-se quase instantâneamente a coagulação. Torna-se de côr parda-amarelada e solidifica-se. As camadas que se formam sucessivamente são retiradas do eixo e são postas ao sol e elas, quando endurecem mais ainda, adquiram entāo aquela côr escura que tôda a gente conhece" (120).

17 En ese sentido considérese lo siguiente: "En el Perú... la explotación de la plata se transformó en la principal actividad económica antes que en México... debido a que los pueblos andinos ya habían desarrollado técnicas sofisticadas de minería y de refinación... en 1545 fueron indios (que trabajaban para españoles) quienes descubrieron Potosí. En esa mina, localizada a mucha altitud, los fuelles europeos eran incapaces de llevar el metal a la temperatura adecuada y entonces la Huayra indígena, o sea un horno para fundir metales construído en las cumbres para tomar ventaja de los fortísimos vientos de Potosí (horno en verdad bautizado así en honor al viento), fue usado para lograr el primer 'boom' de producción, siendo indios quienes realizaron tanto la construcción de los hornos como fundieron el metal. Sin embargo eso no impidió que un español se proclamara su inventor y que estampase la Huayra en su escudo de armas... " ((Lockhart y Schwartz: 101; énfasis nuestro). 
Sobre ese caucho, resultado de la tecnología indígena, los occidentales realizaron sucesivas experiencias que terminaron en la vulcanización en 1839. Charles Goodyear inventó este proceso por casualidad cuando cayó azufre en un horno donde hacía experimentos con caucho indígena. Así se abrió el capítulo de la historia tecnológica conocido como vulcanización. Y éste ha sido el componente esencial de la industria automovilística, símbolo de la economía mundial del Siglo XX. Entonces, esencialmente la vulcanización apareció como resultado de juntar el caucho, resultado de un proceso tecnológico indígena amazónico, con el azufre. O sea que este moderno proceso tiene sus raíces en un proceso técnico indígena tradicional. Pero de ese todo la historia dominante normalmente reconoce sólo a la parte occidental o sea, la de Goodyear (imposible de olvidar debido a la propaganda del gigante mundial de la industria de ruedas que lleva su nombre). En tanto que la parte indígena no sólo ha sido casi totalmente olvidada: los pocos descendientes de los que la inventaron sobreviven en horrenda miseria.

De lo dicho podría concluirse que no es cierto que el progreso lleve naturalmente, desde occidente, tecnología a lugares que no la tenían antes de su llegada. Esa visión prácticamente niega la existencia previa de tecnología en cualquier lugar antes de la llegada de los europeos.. En relación al asunto aqui en estudio se hizo evidente que Verne compartía esa visión eurocéntrica. Los indios de la Amazonía sí tenían tecnología adecuada plenamente a su hábitat. ${ }^{18}$

E. La naturaleza amazónica es presentada por Julio Verne como extremadamente rica y variada. Por ejemplo, narrando un paseo hecho por Minha, Bento, Manuel y Lina por los alrededores de la hacienda de Iquitos, dice:

\footnotetext{
$18 \quad$ O sea que tendría que redefinirse la noción de progreso pues éste, para realizarse, en muchísimos casos expropia y simultáneamente niega la existencia de tecnología (esencial en la idea de progreso) en territorios no-occidentales antes de la llegada de los europeos.
} 
... nada pode haver neste mundo mais belo do que aquela parte da margem direita do Amazonas. Ali em pitoresca confusão cresciam tantas árvores diversas que no limitado espaço de um quarto de legua quadrada podiamse contar 100 variedades de aquelas maravilhas vegetais. $O$ alegre bando ia penetrando na floresta... Na frente ia o prêto manobrando o machado para abrir caminho, o que fazia fugir milhares de aves... Ali estavam representados os mais belos tipos da mitologia tropical. Os papagaios verdes, os periquitos gritadores pareciam ser os frutos naturais daqueles gigantescos troncos. Os pica-flôres e tôdas suas variedades, barba-azuis, rubis-topázios, de longas caudas, apareciam em bandos como se fossem flôres soltas que o vento levasse de um ramo para outro. Melros de penas de côr de laranja debruadas de riscas escuras, papa-figos dourados, sabiás pretos como corvos reuniam-se em um concerto de assobios, verdadeiramente ensurdecedor. O longo bico do tucano desmanchava os cachos de ouro das guiriris. Os picanços sacudiam as pequenas cabeças sarapintadas de pontos escarlates. Era um verdadeiro encanto para os olhos. Mas tudo aquilo se calava, se escondia, quando rangia no cimo das árvores a roufenha voz do alma-de-gato, ave de rapina, de côr clara, que ... fugia covardemente no momento em que aparecia nas zonas supeRiores - gaviāo, enorme águia de cabeza branca como neve... Minha indicava a Manuel aquelas maravilhas da natureza que se encontravam em sua primitiva simplicidade... Ao cabo de uma hora haviam andado apenas dois quilómetros. As árvores mais afastadas da margem do Rio tinham aspecto diferente. A vida animal já não se manifestava à flor da terra, mas sim à altura de 20 ou 30 metros, pela passagem de bandos de macacos, que se perseguima uns aos outros atrvés de ramos elevados. Aqui e além penetravam até ao chão alguns cones de raios solares. Parece averiguado que a luz não é agente indispensável para a existências dessas florestas tropicais. Basta o ar para o desenvolvimento dos vegetais, grandes ou pequenos, árvores ou plantas e todo o calor necessário para a expansão de sua seiva, tiram-no eles, não da atmosfera ambiente, mas do seio do solo, onde se acha armazenado como em enorme calorifero. E sôbre as bromélias, as orquideas, os cactos, numa palavra tôdas as parasitas que formavam uma pequena floresta por debaixo da grande, maravilhosos insetos pareciam verdadeiras flôres. Que maravilhas! Repetia a moça...(50-51). 
En esa larga cita como en otras partes el novelista francés está mostrando la extraordinaria diversidad biológica de la Amazonía. Por eso en los tiempos actuales ha tenido que crearse el concepto de megadiversidad para retratar la riqueza de regiones como la amazónica; sólo otras cuatro del mundo tienen ese rango (Amazonía si mitos: 18). Pero Verne no llama la atención del lector sólo para esa gran diversidad; lo hace también al referirse a la importancia de respetar las cadenas biológicas. En sus palabras: "Devem-se respeitar as seriemas — respondeu Manuel —, porque são grandes destruidoras de serpentes. Pelo mesmo motivo devem-se respeitar as serpentes replicou Bento —, porque comem os insetos nocivos, e êsses também porque se alimentam de pulgóes, que são ainda mais nocivos! Assim, dever-se-ia respeitar tudo! " (52). Aqui Verne está coincidiendo con los principios de la Ecología, disciplina científica que ha tenido un gran desarrollo especialmente en la segunda mitad de este siglo.

Esas citas de Verne muestran su extraordinaria sensibilidad y perspicacia lo que le permitió, como se sabe, entrever el futuro, razón más que suficiente para su merecida fama.

F. La precisión de la información indica que las anticipaciones del futuro de ese escritor se basaban en abundante, buena y actualizada información. Por ejemplo Verne define a Iquitos como una aldea y a Belén como una ciudad. Y eso era totalmente cierto pues Iquitos, hoy la Capital de la Amazonía Peruana - con casi medio millón de habitantes - y tercera ciudad de toda la región (después de las brasileñas Belén y Manaos), comenzó a adquirir importancia sólo a fines de 1853 por una serie de disposiciones gubernamentales del Perú (Rumrill: 18).

Recuérdese que 1852 es la fecha eje de "La Jangada”. Allí está escrito que:

... a Aldeia de Iquitos está situada perto da margem esquerda do Amazonas... [sua] população... era formada não só de indios das diferentes raças... mas também de algums espanhóis e duas ou três famílias de mestiços... 
40 miseráveis choças compunham tôda a aldeia, pitorescamente agrupada numa esplanada que dominava da altura de 20 metros as margems do Río... (24).

Posteriormente, al narrar que el 5 de junio de 1852 la jangada ya terminada se disponía a iniciar su viaje, dice: "Uma tribo inteira de 150 a 200 indios dos arredores de Iquitos, sem contar a população da aldeia viera a assitir ao interessante espectáculo. A multidão olhava e conservava-se quase totalmente silenciosa... "(68). Esa información coincide casi con la siguiente:

... en el censo poblacional llevado a cabo... Iquitos registra un total de 150 habitantes... era el año $1847 . .$. entre ese censo... y el de 1862, en dias de [Iquitos] convertirse en Apostadero Naval [para vapores], la población del lugar habia aumentado totalizando 431 habitantes... (Rumrill: 19).

Verne tiene razón al calificar en 1852 a Iquitos de aldea, y de tildar de maravillosos sus alrededores. Esto último es un gran mérito pues él, sin saberlo con certeza, estaba dando cuenta con gran precisión de un lugar que sólo la ciencia actual ha demostrado que es una auténtica maravilla natural. Así por ejemplo, en el planeta tierra: "el mayor número de especies registradas de árboles está en Yanomomo (cerca de Iquitos) con 300 especies de más de $10 \mathrm{cms}$. de diámetro a la altura del pecho (DAP) por hectárea... y el de reptiles... también... "(Amazonía sin mitos: 19).

Iquitos para Verne era una aldea pero, por su descripción de la hacienda de João Garral, también era un paraíso. Entonces la Amazonía podía ser un paraíso pero también un infierno.

G. La Amazonía como infierno y paraíso está presente en "La Jangada”. Esa balsa parte de Iquitos el 6 de junio de 1852. El 20 de julio llega a Ega (también conocida como Tefé) que es el primer lugar que en la novela tiene el nombre de ciudad. El escritor dice: "Ega... pôrto da antiga Missão, fundada ... pelos Carmelitas, que se transformou em cidade no 1759, e que foi 
definitivamente sujeitada à soberanía brasileira pelo general Gama" (111). Y el lugar es descrito asi: "sem dúvida - respondeu Bento rindo. Mais de mil e quinhentos habitantes, pelo menos 200 casas e duas ou três ruas" (111). Posteriormente se lee que en "Ega havia também dois ou três edificios civis, um quartel e uma igreja, dedicada a Santa Tereza, que era catedral ao pé da modesta capela de Iquitos" (112). Era un lugarcito pequeño. Pero, para las mujeres de la familia Garral era la primera ciudad que conocían y entonces, al desembarcar, quedaron deslumbradas:

". então, cautela, minha mãe e minha irmã-proseguiu Bento-porque vão a cair em verdadeiro êxtase quando chegarem a Manaus, e desmaiarão de prazer quando chegarem a Belém" (111).

Y cuales eran los motivos para el deslumbramiento?. Por ejemplo:

"... mas, para [Minha e Lina] havia outro motivo de pasmo, de pasmo feminino. Eram as modas das elegantes eganas, não o vestuário primitivo do belo sexo indígena, mas o trajar das verdadeiras brasileiras!. Sim, as mulheres, as filhas dos funcionaRios, dos principais negociantes da cidade, vestiam pretensiosamente trajes parisienses!" (112).

O sea que los productos de Occidente penetraban y ocupaban los espacios recónditos de la Amazonía transformando hasta sus usos y costumbres mas típicos:

“... querida Minha - disse Manuel —, com seu vestido de chita, o seu chapéu de palha, pode crer que esta muito mais elegantemente vestida de que todas estas brasileiras de chapéu e laçarotes, que não são própios de seu país nem de sua raça" (112).

Y esa transformación podía tener efectos como el siguiente. Continúa el relato señalando que habían desembarcado para ver Ega y por eso: "passearam... passaram pela praça, ponto de reunião dos elegantes e das elegantes, que suavam com o pêso dos seus vestuários europeus" (112). Por todo esto al final de la visita la familia Garral regresó a la jangada: 
"... com as ilusöes um pouco perdidas, talvez, sôbre as magnificências de uma cidade... um pouco fatigada... com o passeio através daquelas ruas quentíssimas que näo eram nem para comparar em beleza às umbrosas veredas de Iquitos. O entusiamo havia baixado..."(113).

Al final, el contacto con esa ciudad (sería mejor tildarla de villa) resultó un poco decepcionante. Conforme aumentó la decepción, por contraste, la imagen de la aldea de Iquitos fue mejorando. Entonces, sería lícito preguntar si tal decepción no desaparecería si el contacto fuera con una ciudad más grande.

El 24 de agosto La jangada llegó a Manaos. Esa ciudad:

“... não está exatamente à beira do Río das Amazonas, mas, sim, na margem esquerda do Río Negro,... o mais notável dos tributáRíos... descoberto em 1645 pelo espanhol Farela, nasce na vertente das montanhas situadas... no coração da provincia de Popaião, e acha-se em comunicação com o Orenoco,... por dois afluentes, o Pimichim e o Caciquiare". (147).

Continúa la detallada descripción diciendo que después de $1700 \mathrm{Kms}$. llega, a través de una desembocadura de $2 \mathrm{Kms}$. de ancho, y "despeja a suas águas no Amazonas, mas sem que elas se confundam com as dêste último Río, no espaço de muitas milhas... "(147). En ese lugar las márgenes se separan formando una gran bahía; es allí "numa daquelas estreitas enseadas que se abre o pôrto de Manaus... "(147). Verne cree que la transformación de Manaos en escala para vapores hará que su comercio aumente sensiblemente:

“... efetivamente, as madeiras,... o cacau, a borracha, o café, a salsaparilha, a cana de azúcar, o anil, a noz-moscada, o peixe salgado, a manteiga de tartaruga, todos esses diversos artigos encontram [em Manaus] numerosos cursos de água para os transportar em todas as direçōes: o Río Negro para norte e oeste, o Madeira para sul e oeste, o Amazonas [para oeste] $e$ leste, até o litoral Atlantico..." (148). 
Todo eso debido a la situación geográfica de esa ciudad que era "... por tanto, magnifica, e deve contribuir poderosamente para sua prosperidade" (148). Rápidamente y con precisión hace conocer su historia: "Manaus - ou Manao - chamava-se outrora Moura, depois chamou-se Barra do Río Negro. De 1755 a 1804 fazia sòmente parte da capitania que tinha o nome do grande afluente... Mas em 1826, foi elevada à categoría de capital da vasta provincia [hoje Estado] de Amazonas... "(148). Verne informa que Manaos era el nombre de una tribu del lugar, originaria de América Central y por ese su nombre viajantes mal informados la habían confundido con Manoa capital del legendario El Dorado. Pero, dice:

“... em suma, Manaus nada tem dos esplendores fabulosos desta mitológica capital de El Dourado. Não é mais que uma cidade de 5 mil habitantes pouco mais ou menos, 3 mil dos quais pelo menos, são empregados públicos. Há, portanto, certo número de edificios civis para uso desses funcionáRíos: camara legislativa, palacio do governo, tesouraria-geral, correio, alfandega, um colegio que foi fundado em 1848, e um hospital construido em 1851. Quanto a edificios religiosos, há sòmente dois: a pequena igraja da conceiçaô e a capela de Nossa Senhora dos Remédios, situada... num pequeno outeiro que domina Manaus. É pouco para uma cidade de origem espanhola. Devemos ainda acrescentar un convento de Carmelitas, que se incendiou em 1850..."(149) .

Cuenta que 3 calles principales muy irregulares cortaban la ciudad y que alrededor de ellas había otras de tierra cortadas a su vez por 4 canales sobre los que se levantaban pequeños puentes de madera; esos canales en ciertos lugares tiraban "suas águas de côr escura no meio de grandes terrenos baldios, semeados de ervas e de flôres de vistosasa côres" (149).

En relación a su población es enfático al decir que "a população de Manaus näo se eleva acima do número indicado, e compöem-se de funcionarios públicos, negociantes [quase todos] portuguêses e indios das diversas tribos do Río Negro... "(149). Y agrega que las casas particulares eran rudimentarias. 
He ahi el Manaos descrito por Verne. Era obviamente mucho más grande que Ega. Y en esa primera ciudad, capital de la provincia brasileña de Amazonas, João da Costa = João Garral y su muy católica familia descubririan que el infierno verdaderamente existía. Como lo vimos anteriormente el personaje principal pisó la tierra de Manaos ya en calidad de detenido. Allí posteriormente sufrió el tormento de enfrentar la horca, sabiéndose inocente y fue salvado en el último instante. Todo ese proceso puso también en riesgo la existencia de su propia familia. O sea que la ciudad se transformó literalmente en prisión.

Y no sólo eso. Ella también generó decepción. ¿Porqué? La respuesta a eso, parece decir Verne, está en que infelizmente en la ciudad va desarrollándose la falsedad como producto de la imitación (por ejemplo la copia de la moda occidental). Y parece agregar que está también en el hecho de que ella es el lugar de residencia de un inmenso número de funcionarios públicos (o sea, de no-productores). Y más todavía: porque ella está con su naturaleza cortada, dominada, muy limitada (reducida casi, en Manaos, a aguas oscuras que desembocaban en terrenos baldíos con yerbas y flores y en Ega, a calles calentísimas sin sombra).

De cualquier manera, parece también decir Verne, la ciudad era el asiento de los poderes públicos (donde había funcionarios dignos y honestos como el juez Jarriquez) y del comercio regional y transcontinental. Por eso era el asiento de la civilización. Civilización sí, pero que no dejaba de ser también una prisión infernal.

Todo lo anterior contrasta con la descripción hecha por el novelista francés, y que ya vimos, del lugar constituido por la aldea de Iquitos y sus alrededores (que incluye la hacienda y su casa). De la descripción se deduce que ese lugar era paradisíaco. Y lo era porque allí João Garral y su familia fueron libres. Además, porque era un lugar habitado sólo por gente que trabajaba o sea por productores. Productores que en contacto directo con la naturaleza, respondiendo a ella, no imitaban a nadie. Y no necesitaban hacerlo porque por vivir en contacto con una naturaleza salvaje era absolu- 
tamente posible la libertad. O sea que la naturaleza salvaje posibilitaba la libertad, característica del paraíso. ${ }^{19}$

Es bueno anotar que Verne al describir a Ega y a Manaos con sus naturalezas limitadas está prefigurando aspectos esenciales de las ciudades amazónicas de la actualidad que, hasta donde se sabe, parecería que desafortunadamente no fueron organizadas para preservar la naturaleza, sino para todo lo contrario.

Igualmente al describir cómo "los elegantes y las elegantes" de la ciudad imitaban la moda parisina y occidental, Verne está dando un buen ejemplo de una de las enseñanzas claves de la contemporánea teoría de la dependencia. ${ }^{20}$ Pero Verne con su ejemplo va más allá. Con la seguridad que le da su posición eurocéntrica, no duda en ridiculizar esa imitación tropical; él dice "sudaban con el peso de sus vestidos europeos". Sin embargo, parece decir también, que ese efecto perverso era sólo otra de las fatales consecuencias del indetenible avance de la civilización y del progreso (en los que ciudades como Manaos estaban totalmente inmmersas al ser, por ejemplo, escala de vapores que cruzaban fronteras y realizaban comercio trasatlántico).

H. La extrema porosidad de la frontera amazónica llama la atención en "La Jangada". O sea que esa frontera prácticamente no existía debido a que era muy fácil cruzarla. Esto se hace evidente desde las páginas iniciales de la novela cuando Verne muestra al brasileño Torres vagando por la Amazonía peruana, cerca a Iquitos. En esa narración se evidencia que Torres cruzaba la frontera más o menos cuando quería. Y eso era muy frecuente, se deduce, debido a su profesión de cazador de esclavos que huían. Lo

19 Es claro que el contraste hecho por el francés Julio Verne entre ciudad (civilización = prisión) y aldea (salvaje = libertad) está reflejando directamente el mito iluminista del buen salvaje. Y en ese nivel el novelista coincide casi totalmente con el romanticismo ya mencionado de Valdez. en ellos y por eso copian, imitan, piensan, imaginan ser occidente. 
mismo puede concluirse en relación a João Garral: él simplemente huyó y cruzó la frontera. Y el gran amigo de Torres, el verdadero autor del crimen de Tijuco, Ortega, queda claro que igualmente cruzaba la frontera cuando lo necesitaba; y esa necesidad debía ser frecuente debido a que tenía la misma profesión de Torres. Precisamente en una de esas oportunidades en que cruzó, vio y reconoció a Garral.

A partir de las referencias de Verne en relación a su personaje Manuel Valdez algo similar puede concluirse. Este, por su amistad con Bento, iba con frecuencia a pasar vacaciones en Iquitos. Y también de Bento quien vivía en su hacienda peruana, pero estudiaba en Belén. Algo parecida era la situación del Padre Pasanha: ejercía su ministerio en Iquitos pero dependía de Belén; por eso viajaba a esa ciudad para jubilarse. O sea que estos tres también pasaban la frontera a menudo.

En toda su novela Verne nunca mencionó siquiera la posibilidad de que, para cruzar la frontera, alguno de los arriba mencionados perdiera aunque sea un instante consultando previamente a alguna autoridad, brasileña o peruana.

Entonces la sensación que se obtiene al leer esa novela es que los brasileños cruzaban la frontera amazónica con enorme facilidad o sea, como dice el dicho popular, "entraban y salían como si fuera su casa". Como no era siquiera necesario consultar a alguien para cruzar la frontera, de la novela se desprende que ella, en la práctica, no existía. ${ }^{21}$

21 De esa manera lo que Verne hacía era retratar una realidad evidenciada por el hecho histórico de la expansión del Brasil en base a cruzar fronteras. Expansión que cualquiera puede deducir después de comparar los mapas publicados por el Ministério de Educação e Cultura do Brasil (V. "Mapa Econômico do Brasil: Siglos XVI, XVII, XVIII e XIX". In Novo Dicionário... pp. 81, 97, 113 y 128). La facilidad de ese cruce, desde los tiempos coloniales, fue demostrada por los bandeirantes ("participante de una bandeira ou expediçăo destinada a explorar minas ou apresar índios”: Koogan y Houais: 105). Estos iniciaron la expansión que culminó con un territorio gigantesco para el Brasil. Y eso favoreció el establecimiento, por parte de este país, de la política basada en el principio utis-possidetis (lo que habitas, 
Ahora, en relación a nuestro trabajo es oportuno mencionar que, gracias a la gran porosidad fronteriza es que José Manuel Valdez y Palacios pudo huir al Brasil y escribir allí su obra. Por lo tanto sería legítimo decir que si bien lo establecido anteriormente era cierto, también lo era lo siguiente. De alguna manera Julio Verne y Valdez y Palacios al mostrar la gran porosidad de la frontera mostraban que ella no existía porque estaba integrada.

I. La integración del espacio amazónico parece ser una aspiración común del novelista francés Julio Verne y del escritor peruano José Manuel Valdez y Palacios.

El último capítulo de "La Jangada” tiene por título "O Baixo Amazonas". Está dedicado a narrar el viaje de Manaos a Belén de la felicísima familia de João Garral después que éste es liberado. Su descripción es la de siempre o sea muy rica en información. Pero sólo las cuatro últimas páginas son dedicadas a Belén. Allí dice:

"... finalmente apareció á esquerda Santa Maria de Belém do Pará, a cidade, como the chaman, com a suas pitorescas filas de casas brancas de muitos andares, os seus conventos circundados de bandeiras, as tôrres de sua catedral e de Nossa Senhora das Mercês, a sua flotilha de escunas, brigues-barcas, que a põem em relaçôes comerciais com o Velho Mundo... No dia 5 de outubro - quatro meses e meio depois de terem deixado a fazenda de Iquitos - apareceu-lhes Belém... centenas de embarcaçôes vieram a seu encontro..." (260-61)

El 16 de octubre el Padre Pasanha realizó en la jangada el matrimonio de Manuel Valdez con Minha y del peluquero Fragoso con Lina. Estos

poseerás). La porosidad de las fronteras, especialmente amazónicas, abrió la posibilidad para que de manera sagaz, primero por portugueses y después por brasileños, ese país esgrimiera ese principio aceptado internacionalmente; consolidando así sus muy ampliadas fronteras (se recomienda leer las notas que acompañan esos mapas). 
matrimonios fueron hechos con gran pompa pues entre los asistentes estuvieron hasta el Gobernador de Belén y los compañeros del médico-militar Manuel. Al casarse repiquetearon las campanas de las iglesias de Belén, retumbaron descargas de armas de fuego y las banderas de los barcos del puerto subieron al tope: "e as côres brasileiras foram saudadas pelos pavilhóes nacionais dos outros países" (262).

Después del matrimonio se decidió regresar:

“... efectivamente, Manuel Valdez tencionava pedir sua demissão para ir com tôda a familia para Iquitos, donde teria com certeza ensejo de exercer com proveito sua profissão... A mãe de Manuel... não quisera separar aquela bõa gente. Mas pusera uma condição: era que haviam de vir a vêla muitas vezes em Belém. Nada seria mais fácil. Não havia ali o grande Río, como um laço de comunicação que não devia quebrar-se mais entre Iquitos e Belém? Efetivamente, ia eçar alguns dias depois, o serviço regular e rápido de barcas, que não gastariam mais de uma semana em subir o Rio que a jangada levara tantos meses a descer.. o fazendeiro, sua mulher, seu filho, Manuel y Minha Valdez, Lina e Fragoso tornaram a partir a bordo de uma das embarcaçōes do amazonas regresando à fazenda de Iquitos, cuja direção ia ser entregue dai por diante a Bento..." (263).

Cinco líneas después, termina la novela.

Parece obvio que Verne tenía la esperanza de que la región amazónica, comunicada cada vez con más grande frecuencia y rapidez, operara de manera integrada como si no tuviera fronteras. Y vale nuevamente reconocer la precisión de su información pues casi exactamente un año después de los hechos que él acaba de narrar:

“... un 7 de octubre del año 1853, tan lleno de acontecimientos, arribaba a Loreto [Iquitos] el vapor brasileño Marajó... iniciando la era de la navegación a vapor en la Amazonía Peruana. Por otra parte, no tardarían en llegar desde Estados Unidos los vaporcitos Tirado y Huallaga, con 
los cuales se trataría de establecer líneas de navegación atendidas por unidades [peruanas]..." (Rumrill: 19).

Y el escritor peruano, años antes que el novelista francés, también veía la frontera amazónica como una línea no para separar, sino para integrar. Esto se señaló anteriormente al informar sobre él. Pero aquí es oportuno subrayar su opinión:

“... trazado el recorrido del Cuzco al Pará,... indicadas las producciones posibles,... nacidas con tanta abundancia en aquellos climas deliciosos... entonces las aguas... se verán surcadas por embarcaciones llenas de vida y actividad; entonces las ricas producciones de estos paises, aumentadas y mejoradas por la mano de la industria, multiplicarán también los goces de la existencia...." (Valdez y Palacios a: 7).

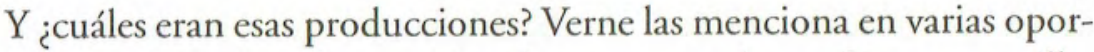
tunidades: maderas (muchas preciosas), cacao, caucho, café, zarzaparrilla, caña de azúcar, añil, nuez moscada, pescado salado, manteca de tortuga, etc. Tratándose de la Amazonía obviamente que llama la atención el caucho ("borracha"). La explotación de ese bien, originario de esa región, llegó a ser tan importante que determinó la constitución de todo un ciclo económico. Por ejemplo, en el ya mencionado Mapa Econômico do Brasil do Século XIX, puede leerse: "en la economía del Siglo XIX, surgen dos productos de enorme importancia... el caucho, que durante un tiempo tuvo gran comercio y, en Río de Janeiro y São Paulo, [el ciclo del] café.. ". El caucho determinó todo un ciclo que no se limitó al Brasil: toda la región tenía ese bien y por eso fue un ciclo de todos los países amazónicos.

A pesar de su importancia Verne trató sólo de manera circunstancial al caucho. Por ejemplo, al describir el método indígena para extraerlo, que ya se transcribió, también decía:

“... havia ali um seringal. Êste nome provém do nome da árvore da borracha, seringueira, cujo nome científico é simphonia elástica. Diz-se 
que, por negligência, ou má exploração, o número dessas árvores diminui na bacia do Amazonas. Mas as florestas de seringeira são ainda considerabilíssimas nas margens do Madeira, do Purus e outros afluentes do Río [Amazonas]"(120).

Prácticamente sólo eso es lo que dice sobre el caucho en "La Jangada". Muestra sí que ya era un producto muy explotado al punto que ya había desaparecido en algunas regiones. Pero no proporciona ningún indicador de la importancia de ese bien cuyo ciclo de explotación marcó de manera indeleble la historia de los países que comparten la Amazonía.

¿Porqué el novelista francés no le dio al caucho el tratamiento que merecía? Tal vez, como la historia enseña, porque la fase fundamental de ese ciclo ocurrió después de 1880. "La Jangada", como se sabe, fue publicada en 1881; por lo tanto cuando fue escrita todavía no era notoria la enorme relevancia del caucho en la economía mundial (que llegaría a su cúspide con el desarrollo pleno de la industria automovilística). ${ }^{22}$

Lo anterior permite entender las probables razones del novelista francés para prestarle poca atención al caucho: escribió cuando éste comenzaba a adquirir peso mundial. Las mismas razones explican, y todavía más, el hecho de que Valdez y Palacios, en sus publicaciones conocidas, prestara aun menos atención a ese bien: escribió casi 40 años antes que Verne.

\footnotetext{
22 Cuando se escribía esa novela el caucho, ya vulcanizado, se usaba principalmente en ruedas de bicicletas y en la naciente industria motociclística. O sea que el caucho, conforme se acentuaba la industrialización, era cada vez más requerido. Por eso en 1876 el inglés Henry Wickham seleccionó y robó del Brasil semillas de ese árbol (por lo que mereció el título de Sir). Las semillas, llevadas y debidamente aclimatadas en The Royal Botannical Garden of Kew Gardens, Londres, fueron después trasladadas a las colonias británicas de Asia. Esas plantaciones, relativamente pequeñas, fueron organizadas para producir en escala industrial (casi ilimitada). Por lo tanto eran diferentes a los gigantescos territorios amazónicos organizados alrededor del artesanal extractivismo natural (limitado). Pero todo eso, combinado, fue determinando un progreso que inició la fase más importante del ciclo del caucho por los años de 1880 o sea, cuando Verne publicaba su novela.
} 
Otro producto amazónico de importancia mundial es la quinina. Y llama la atención que no existan menciones a ella en "La Jangada". La quinina, también conocida por sus nombres ingleses de "Chinchona Bark" o "Peruvian Bark", es otra muestra de la extraordinaria riqueza natural de la Amazonía. Ella también jugó un destacado papel en la historia económica mundial.

La era del automóvil es tal vez la marca de la historia económica del Siglo XX. La era del ferrocarril es su equivalente en el Siglo XIX. A partir de 1850 el ferrocarril posibilitó vincular la economía del interior con los puertos costeros (eso es conocido como el ciclo de apertura del interior de los continentes). Pero era muy dificil abrir los continentes tropicales debido a que enfermedades, transformadas en pestes como la malaria, atacaban y mataban en masa a los trabajadores que instalaban las vías férreas. Fue entonces que la ciencia occidental aceptó y generalizó la cura en base a la corteza del árbol que una indígena había usado para curar, en 1638, a la esposa del Virrey del Perú Conde de Chinchón. Por eso es que a fines de la década de 1850 el geógrafo inglés Clements Markham (también hecho "Sir", al igual que Wickham), comandó un equipo de botánicos que, a partir del Perú, recorrieron toda la Alta Amazonía desde Bolivia hasta Venezuela, recogiendo todas las variedades de semillas del árbol de la Quina (de cuya corteza se extrae la quinina). Después, en el Puerto de Islay, acomodaron todas las semillas en un barco especialmente acondicionado que esperaba. Antes de partir una autoridad de ese puerto intentó pedir explicaciones sobre ese robo; Sir Clements no dudó y amenazó con una pistola a ese hombre que, según sus palabras, con su acción estaba oponiéndose al progreso. El barco partió; su carga llegó al mismo jardín del Gobierno Británico que, más de una década después, acogería también a las semillas del caucho. Posteriormente brotes seleccionados del árbol de la Quina fueron trasladados y transplantados en plantaciones especialmente preparadas en su colonia de la India (Markham).

De esa manera fue posible obtener el antídoto que le permitió, a la industria ferrocarrilera, finalmente abrir el interior de los continentes tro- 
picales (i.e. India, Africa, América Latina). También así se sentaron las bases para consolidar la moderna industria farmacéutica de comprimidos (o sea, producción de medicamentos en gran escala).

El árbol de la quina es casi tan importante como el del caucho para la historia amazónica. Pero el impacto del primero fue más limitado debido a que no se da en la Baja Amazonía que forma más del 80 por ciento de esa región. Toda la Amazonía brasileña forma parte de la Baja Amazonía. Sólo los países Andino-Amazónicos poseen Alta y Baja Amazonía.

Como la novela de Verne trata del territorio comprendido entre Iquitos y Belén (Baja Amazonía), donde no se encuentra al árbol de la quina, tal vez por eso él consideró que no era importante mencionarlo. Por su parte Valdez y Palacios escribió mucho antes de que la quinina adquiriera significado mundial.

J. La religiosidad católica de Verne es evidente en su novela amazónica. Por ejemplo él dice:

“... assim como o piloto era o guia material daquela imensa [balsa], outro personagem ia ser seu guia espiritual: era o padre Pasanha, diretor da missão de Iquitos. A familia de João Garral, que era religiosíssima, havia manifestado o maior entusiasmo por ter aquela ocasião de levar consigo [na Jangada] um velho padre que venerava... Passanha, que tinha então 70 anos de idade, homem de bem, cheio de fervor evangélico, caritativo e bom, no meio daquelas regioes onde os repressntantes da religião nem sempre dão exemplo de virtudes, aparecia como o tipo completo desses missionários que tanto têm feito pela civilização nos pontos mais selvagens do mundo..." (66).

La evidente admiración del novelista francés por los misioneros católicos es casi un reflejo de la opinión siguiente: 
"... Cuán impios son aquellos que hablan mal de los misioneros! Se olvidan por ventura de los beneficios que han hecho a la humanidad? La civilización americana, no está llena de recuerdos del celo que desplegaron en la prédica del evangelio? Su valor, su abnegación, su constancia, dieron a sus trabajos apostólicos un carácter de heroísmo que sólo pueden negarles aquellos que los juzgan con prejuicio o que los desconocen por ignorancia... [los misioneros] unos cuantos, sin más armas que las de la persuasión, recorrieron los parajes más apartados del Globo, para rescatar de la vida salvaje a los más indómitos moradores..." (Valdez y Palacios: 21)

El Padre Passanha es presentado por Verne como un personaje lleno de virtudes. De alguna manera parece que él formaba parte de la estirpe de misioneros cuyo arquetipo fue Samuel Fritz. Este último, germánico, parece ser el modelo paradigmático de referencia a partir del cual se han construido, en novelas, los misioneros heroicos amazónicos. Por ejemplo, según Neide Gondim, ese es el caso de Vicky Baum para crear al Padre Anselmo Pfungst de su novela $A$ árvore que chora. O romance da borracha (Gondim: 212-213, 217).

Samuel Fritz existió. Un estudioso dice que entre los misioneros que ejercieron su ministerio en la Amazonía del Virreinato Peruano:

"... la más extraordinaria y prestante figura es la del P. Samuel Fritz (1654-1725)... natural de Bohemia... ingresado en la Orden [Jesuita] en 1673,... Ilegado a las selvas amazónicas en 1685, las cuales exploró primeramente desde el Napo hasta el Río Negro, a partir del año de su llegada hasta su fallecimiento... Su Diario o Tagebuch descubierto por George Edmundson sólo hace pocas décadas, en Evora, Portugal, ilustra fehacientemente acerca de la extensión de sus exploraciones y su calidad científica en el campo de la geografía y la etnología. Realiza los primeros estudios de las tribus Omaguas, Cocamas, Yurimaguas, Aysanares, Banomas y otras... De él sólo se conocía su famoso Mapa del Amazonas reproducido por La Condamine en su relación de viaje, y el tercero que se 
publicó hasta la fecha de su publicación en Quito, 1707..." (Núñez 1989: 108).

Fritz fue un infatigable viajero. Llegado al Virreinato Peruano, se instaló en la Ciudad de Quito de donde:

“... se traslada, surcando los Ríos Napo, Negro y el Marañón (1687) a la vasta región del gran Río. Al poco tiempo navega el Amazonas en toda su extensión desde Yurimaguas hasta Pará (1689). Detenido por las autoridades portuguesas... permanece en Pará cerca de dos años, creyéndosele perdido en las selvas, ahogado en los Ríos o sacrificado por los naturales. Después de muchas gestiones de su orden ante la corte de Lisboa, obtiene la libertad y regresa al Marañón (1691). Al poco tiempo decide dirigirse a [la Capital Virreinal] Lima..." (Núńez 1989: 109)

¿Porqué Fritz fue apresado?. Porque enfermó gravemente de malaria en tanto vivía y trabajaba en una aldea Yumaragua o Yurimagua (la primera palabra se usa en el Brasil y la segunda en el Perú). Incapacitado para subir por el Río:

“... decidiu descer o Amazonas e encontrar os portugueses... foi levado por indios para a missäo dos mercedários, na cidade de Silves, onde foi tratado com grande carinho, mas sua saúde não fez progresos... então, o mandaram para Belém, onde foi recebido e tratado pelos jesuitas, recuperando a saúde. Ao tentar voltar para o trabalho missionário, as autoridades portuguesas o detiveram..." (Souza: 57 ).

El territorio donde Fritz desarrolló lo principal de sus acciones, fue el Maynas Colonial. Allí fue "principal de la Orden Jesuita" (Rumrill: 12). Los portugueses lo detuvieron porque en 1687 Fritz había estado organizando misiones en territorio que consideraba eran de Maynas o sea, de la Corona de Castilla. Entonces, cuando haciendo ese trabajo se encontraba cerca a Tefé, desembarcaron soldados portugueses acompañando al Provin- 
cial de los Carmelitas Frei Manoel de Esperança. Después de una discusión entre los dos religiosos: "Fritz não teve outro remédio que se retirar para uma regiāo onde hoje é território peruano" (Souza 57).

Pero las razones de fondo que explican los problemas de Fritz con las autoridades portuguesas está en que él:

“... combatió tenazmente la esclavitud en la Amazonía... para impedir que el Pueblo Yurimaguas fuera esclavizado, lo trajo desde su antiguo asentamiento en territorios que hoy son del Brasil y lo ubicó primero donde [actualmente] queda la Reserva Nacional Pacaya-Samiria y luego lo llevó a donde hoy está Yurimaguas" (Barletti 1995: 37).

Claro, eso explica porque Fritz se enfermó en una aldea Yurimagua. Y el hecho de que la esclavitud amazónica indígena fuera generalizada en el Brasil Colonial lo muestra la estudiosa Neide Gondim al decir que el personaje de novela Padre Anselmo Pfungst (basado, como vimos, en Fritz), tenía: "outro inimigo [que o] atormentava: os portugueses cristãos que roubavam mulheres, crianças e rapazotes para thes servirem de escravos" (Gondim: 213). Igualmente, en su libro Souza hace varias referencias en el mismo sentido (Souza: $35,37,54)$. Y, como ya quedó establecido, esa era una de las principales actividades de los bandeirantes.

Pero todo esto tiene relación con nuestro estudio porque Verne, sin mencionarlo, narra los acontecimientos que fueron desencadenados por Fritz. Dice:

“... Entretanto, o Brasil tive de intervir para impedir o rapto dos indios do Amazonas, que se fazia em proveito das Missōes [dos] hispanos... Eo meio de que lançou mão para se opor a êste abuso foi fortificar a Ilha de Ronda, que se acha um pouco acima de Tabatinga e de estabelecer ali um pôsto militar. Foi uma solução como outra cualquer e, a contar desta época, a fronteira dos dois paises passou pelo meio da ilha. Para acima, o Río é peruano... para baixo, é brasileiro" (86). 
Pero el asunto fue mucho mas dramático como puede concluirse de lo dicho por un importante investigador:

"... Samuel Fritz vai continuar exerciendo enorme influência entre os indigenas... a ponto de o próprío Rei de Portugal, Dom Joào V, ordenar a total expulsão dos jesuitas espanhóis que estavam entre os omágua e a prisão de Samuel Fritz. No dia 24 de dezembro de 1709, o governador de Pará escreveu ao Rei de Portugal que uma tropa de cento e cinquenta soldados tinha sido enviada para acabar de uma vez por todas com a ousadia dos jesuitas espanhóis. O resultado da expedição, além da destruição das missóes e prissāo de algums missionáríos, foi a quase extinção dos omágua" (Souza: 57) .

Regresando al Padre Passanha. Verne no muestra ninguna característica heroica de ese padre pero, de la cita anterior que hizo referencia a él, puede colegirse que por sus acciones logró ser amado y respetado como lo fue Fritz. El novelista agrega que:

"... havia 50 anos que o padre Passanha vivia em Iquitos, na missão de que era chefe. Era mado por todos, e bem o merecia. A família Garral tinhale grande estima. .. A idade do padre... não le permitia exercer por mais tempo o seu laboRíoso mister. Havia soado para êle a hora do descanso. Acavaba de ser substituído em Iquitos por um missionáRío mais jovem e dispunha-se a voltar a Pará, para ai acabar o seus dias num dos conventos reservados aos velhos servos de Deus" (66-67).

Lo anterior significa que en términos de la Iglesia Católica Iquitos dependía de Belén. En segundo lugar podría interpretarse también como que el trabajo de la iglesia se inició antes en la Amazonía brasileña y después en la correspondiente al Virreynato del Perú (recuérdese que, en los tiempos coloniales hasta 1739, el único virreynato consolidado de España en América del Sur era el peruano).

En relación a lo primero podría decirse que de libros como los de Barletti y Rumrill se deduce lo siguiente. Iquitos, como parte del Maynas Colonial, tenía su propio obispado desde 1808: "el primer Obispo de Maynas, 
Hipólito Sánchez Rangel, llegó a Jeberos [entonces capital de Maynas] en abril de 1808" (Barletti 1995: 46). Por lo tanto en el periodo que Verne trata en su novela, los religiosos que actuaban en Iquitos dependían del Obispado instalado en territorio peruano.

En relación a lo segundo. Por ejemplo el Padre Gaspar de Carvajal, cronista de la expedición de Orellana, llegó al Perú en 1530. Era de la Orden de Santo Domingo y en 1538 era Vicario Provincial en Lima. Se unió a Gonzalo Pizarro cuando éste, hecho Gobernador de Quito por su hermano Francisco (primer gobernante europeo del Perú), iba a esa ciudad desde el Cuzco para hacerse cargo de su puesto. Ya en Quito acompañó a ese gobernador que continuaba con su expedición al oriente de los Andes buscando las tierras del clavo, la canela y el oro. Carvajal terminó formando el grupo de Orellana (lugarteniente de Gonzalo) que terminó descubriendo el Amazonas para Occidente (Barletti 1992). Igual podría decirse del Padre Acuña, cronista de la expedición de regreso desde Quito del portugués Pedro Teixeira quien, entre 1637 y 1639, realizó el "Segundo Descubrimiento del Amazonas" (de Belén a Quito y viceversa). Acuña salió de la ciudad de Quito que entonces y hasta 1739 (cuando pasa a formar parte del Virreynato de Nueva Granada) formaba parte del Virreynato del Perú ${ }^{23}$. Finalmente: "a colonização portuguesa... de 1700 a 1755, [realizou o] estabelecimento do sistema de missōes religiosas e de organização política da colônia... "(Souza: 52). En tanto que en el Virreynato peruano: "entre 1639 y 1769 se iniciaron y tuvieron su apogeo las misiones religiosas en la Amazonía. Fueron principalmente jesuitas y franciscanos, respectivamente a partir de Quito y Lima... Iniciaron esas actividades ya en 1611... " (Dourojeanni: 50). Todo indica entonces que fue en el Perú que se iniciaron los trabajos de la Iglesia Católica en la región amazónica.

23 Es sabido que el Gobernador de Quito, temeroso de la presencia de esos portugueses allí en los Andes, tan lejos del Atlántico, impuso Acuña la presencia deTeixeira. Gracias a ese padre español se conoce la realización de ese viaje, pero no de su primera parte (de Belén a Quito). 
Lo anterior permite concluir que la historia no sustenta la posibilidad de que, en términos religiosos, Iquitos haya dependido de Belén. Parece que fue una licencia del novelista Verne (a la que él tiene todo derecho) la que creó esa posibilidad. ${ }^{24}$

K. El Pacífico es absolutamente secundario en "La Jangada". Las pocas menciones a ese océano son hechas por Verne en la parte final del libro. Especialmente cuando Bento y Manuel Valdez, desesperados porque no se encontraba la fórmula para traducir el criptograma que probaría la inocencia de João da Costa= João Garral, inventan un plan de fuga. Con una sierra ellos cortarían las barras de hierro y después, salido ya de la cárcel, João tendría que:

“... embarcar na piroga... seguir o canal até o Río Negro, descer... até o ponto em que se reúne ao Amazonas, depois deixar-se ir com a corrente deste ultimo Río... de modo a chegar assim ... ao Madeira. Este tributáRío, que desce da vertiente da cordilheira, engrossado por centenas de afluentes de segunda ordem, é uma verdadeira via fluvial até o coração da Bolivia" (235)

Después allí, si fuera necesario, podría esperar hasta por varios meses aguardando el momento oportuno: "para se dirigir ao litoral do Pacífico e embarcar em navio que estivesse a partir para um dos postos da costa" (235). La salvación entonces era llegar por el Madeira hasta el centro de Bolivia; después seguiría hasta uno de sus puertos para expatriarse pues era menos peligroso: "o litoral do Pacifico do que no Atlántico" (237).

Es bueno decir aqui que hasta admirables misioneros como Samuel Fritz no están exentos de criticas. El también fue un etnocida: no respetó la otredad indígena. Fritz, al igual que todos los misioneros (reales o imaginarios), fueron y son culpables de religiocidio. Literalmente con la cruz, símbolo de la civilización occidental, destrozaron los dioses indígenas, sinónimos de salvajismo. Sin duda que misioneros de la talla de Fritz arriesgaron sus vidas y llegaron al extremo de robar los cuerpos de los indígenas para salvarlos ya que tenían la obligación de ganar sus almas, pero al costo de hacer un transplante en sus cerebros. Esa es otra dimensión del destructivo proceso de dominio de Occidente sobre la América Indígena. 
La ruta sugerida por Verne, que como se vio también une la Amazonía con los Andes, no es la que usó José Manuel Valdez y Palacios al huir. Ahora, en la ruta de Verne llama la atención que ella sea hecha a través de Bolivia. Llama la atención por la claridad de su información. Eso porque cuando Verne publica "La Jangada", ya Bolivia había perdido sus puertos en el Océano Pacífico puesto que Chile los había anexado a su territorio. Sin embargo, en el año 1852, cuando Verne ubica los acontecimientos de su novela, Bolivia todavía no era un país mediterráneo.

L. El ficcional Manuel Valdez es el "alter-ego" de Verne. Por ejemplo Neide Gondim, a pesar de que con frecuencia olvida el nombre de Manuel y lo llama de Miguel, hace notar que él es el que cita a Humboldt, recuerda historias, da muchas informaciones zoológicas, botánicas y antropológicas, informa técnicamente sobre la tonalidad de las aguas del Amazonas, deshace la leyenda de las amazonas, etc. O sea que Verne a través de él pasa al lector: "variadas e multiples informaçōes históricas e geográficas" (Gondim: 164). Igualmente Manuel Valdez le sirve a Verne para crear muchos: "pretextos que o encaminham a dissertar sobre a regiáo imensa" (Gondim: 164).

O sea que es posible afirmar que el ficcional médico Manuel Valdez es el "alter-ego" de Verne. Tal vez ese fue el medio que el gran novelista francés encontró para homenajear al verdadero Doctor José Manuel Valdez y Palacios. 


\section{BIBLIOGRAFÍA}

AMAYO Z., E.

1995 "La transoceánica Perú-Brasil: los contradictorios intereses de Estados Unidos y Japón". En: Allpanchis. Año XXVII, no 5 . Cuzco.

AMAYO Z., E.

1993 "Da Amazônia ao Pacífico cruzando os Andes. Interesses envolvidos na construção de uma estrada, especialmente dos EUA e Japão". Revista do Instituto de Estudos Avanzados 17. Universidad de Sao Paulo.

BID-PNUD-TCA

1992 Amazonía Sin Mitos. Washington.

BARLETTI, J.

1992 Los Pueblos Amazónicos en Tiempos de Orellana. CETA. Iquitos.

BARLETTI, J.

1995 La Peruanidad de Maynas. J \& M Editores. Iquitos.

CARVAJAL, F.G. de.

1955 Relación del Nuevo Descubrimiento del Famoso Río de Las Amazonas. Fondo de Cultura Económica. México.

DOUROEJANNI, M.J.

1990 Amazonía : Que hacer. CETA, Iquitos..

EDIÇÕES MELHORAMENTOS

1970 Novo Dicionário de Historia do Brasil. Sao Paulo.

GONDIM, N.

1994 A Invenção da Amazônia. Editorial Marco Zero. Sao Paulo. 
HEYERDHAL, T.

1996 Seafaring in Yearly Perú. Instituto Histórico Marítimo del Perú. Lima.

HOBSBAWM, E.J.

1988 A Era dos Impérios. 1875 - 1914. Editorial Paz e Terra. Río de Janeiro

KIERNAN, V.G.

1969 The Lords of Human Kind. Black Man, Yellow Man, And White Man in an Age of Empire. Little Brown and Co. Boston y Toronto.

KOOGAN, A. - HOUAIS, A.

1994 Enciclopédia e Dicionário Ilustrado. Ediçōes Delta. Río de Janeiro.

LISBOA, K.M.

1997 A Nova Atlântida de Spix e Martius: Natureza e Civilização na Viagem pelo Brasil. (1817-1820) Editorial HUCITEC. Sao Paulo.

LOCKHART, J. - SCHWARTZ, S.B.

1983 Early Latin America. A History of Colonial Spanish America and Brazil. Cambridge University Press.

MARKHAM, C.L.

1880 Peruvian Bark. A Popular Account of the Introduction of Chinchona Cultivation in to British India. John Murray. Londres.

MENDIBLE. Z, A.

1995 La Familia Río Branco y la Fijacion de las Fronteras entre Venezuela y Brazil. Academia Nacional de la Historia, Fuentes para la Historia de la República de Venezuela. Caracas. 
NÚN̄EZ, E.

1971a "Estudio Preliminar". Viagem da Cidade do Cuzco a de Belém do Grão Pará pelos Ríos Vilcamayu, Ucayali e Amazonas. Edición de la Biblioteca Nacional del Perú. Lima.

NÚÑEZ, E.

$1971 b$ “Estudio Preliminar”. Bosquejo sobre el estado político, moral y literario dell Perú en sus tres grandes épocas. Edición de la Biblioteca Nacional del Perú. Lima.

NÚNEZZ, E.

1980 Viajeros por América Latina. Colección Ayacucho. Caracas.

NÚÑEZ, E.

1985 España Vista por Viajeros Hispanoamericanos. Instituto de Cooperación

Iberoamericana. Madrid.

NÚÑEZ, E.

1989 Viajes y Viajeros Extranjeros por el Perú. Apuntes Documentales con Algunos Desarrollos Histórico - Biográficos. CONCYTEC. Lima. 1989.

RUMRRILL, R. (et. $a l$ )

1983 Iquitos, Capital de la Amazonía Peruana. Iquitos.

SOUZA, M.

1994 Breve Historia da Amazonía. Editora Marco Zero. Sao Paulo.

VALDEZ y PALACIOS, J.M.

1971a Viagem da Cidade do Cuzco a de Belém do Grão Pará pelos Ríos Vilcamayu, Ucayali i Amazonas. Edición de la Biblioteca Nacional del Perú. Lima. 
Amazonía Peruana

VALDEZ y PALACIOS, J.M.

1971b Bosquejo sobre el estado Político, moral y literario del Perú en sus tres grandes épocas. Edición de la Biblioteca Nacional del Perú. Lima.

VERNE, J.

1966 A Jangada. Editora Matos Peixoto. Río de Janeiro. 